\title{
FORMULASI DAN KARAKTERISASI FISIK MASKER GEL PEEL- OFF EKSTRAK LENGKUAS (Alpinia galanga, (L.) Sw)
}

\author{
Mar'atus Sholikhah $^{* 1)}$, Rahayu Apriyanti ${ }^{2)}$ \\ ${ }^{1}$ Program Studi S1 Farmasi Sekolah Tinggi Ilmu Farmasi Yayasan Pharmasi \\ Jalan Letnan Jendral Sarwo Edie Wibowo Km. 1 Plamongansari, Pucanggading, Semarang \\ ${ }^{2}$ Program Studi S1 Farmasi Sekolah Tinggi Ilmu Kesehatan Mandala Waluya \\ Jalan Jendral AH. Nasution Kambu, Kendari, Sulawesi Tenggara \\ "E-mail:mara.tush@yahoo.com
}

\section{INTISARI}

Alpinia galanga, (L.)Sw atau lengkuas banyak dimanfaatkan oleh masyarakat Indonesia sebagai bumbu masakan. Kandungan katekin dan 1'-asetoksikavikol asetat di dalam ekstrak diketahui memiliki aktivitas antioksidan. Kemampuan antioksidan tersebut perlu diaplikasikan ke dalam bentuk sediaan farmasi untuk meningkatkan estetika dan kemudahan dalam penggunaan. Salah satu sistem penghantaran obat topikal yang sesuai dengan kebutuhan masyarakat saat ini adalah bentuk sediaan masker gel peel-off. Tujuan penelitian ini untuk mengetahui pengaruh variasi konsentrasi gelling agent PVA sebagai basis masker terhadap karakteristik fisika masker gel peeloff ekstrak lengkuas. Tiga formula masker dibuat berdasarkan variasi konsentrasi PVA pada rentang 5\%-15\%. Karakterisasi fisika sediaan meliputi uji organoleptis, homogenitas, pH, viskositas, daya lekat, daya sebar, dan waktu mengering. Data hasil parameter homogenitas dan organoleptis dianalisis secara deskriptif. Parameter viskositas, waktu mengering, $\mathrm{pH}$, daya sebar, dan daya lekat dianalisis secara statistik menggunakan Anova Single Factor dengan taraf kepercayaan 95\%. Hasil penelitian menunjukkan bahwa formula F1 dan F2 dengan konsentrasi PVA $10 \%$ dan 12,5\% merupakan formula optimum sebagai basis masker. Berdasarkan uji statistik, variasi konsentrasi PVA berpengaruh signifikan terhadap parameter daya lekat masker dengan nilai p-value sebesar $0,0001(<0,05)$, sedangkan parameter viskositas, $\mathrm{pH}$, waktu mengering, dan daya sebar menghasilkan nilai yang tidak berbeda signifikan.

Kata kunci: ekstrak lengkuas, Alpinia galanga, masker gel peel-off

\section{ABSTRACT}

Alpinia galanga (L.) Sw or galangal is widely used by Indonesian people as a spice in cooking. The content of catechins and 1-acetoxicavicol acetate in the extract is known to have antioxidant activity. The ability of these antioxidants needs to be applied to pharmaceutical dosage forms to improve aesthetics and ease of use. One of the topical drug delivery systems that is in accordance with the needs of the community today is the preparation of peel-off gel mask. The purpose of this study was to determine the effect of variations in PVA gelling agent concentration as a mask base on the physical characteristics of galangal extract peel-off gel masks. Three mask formulations were made based on variations in the concentration of PVA in the range of 5\%-15\%. The physical characterization of the preparations included organoleptic tests, homogeneity, pH, viscosity, adhesion, dispersion, and drying time. Homogeneity and organoleptic parameters were analyzed descriptively. The parameters of viscosity, drying time, $\mathrm{pH}$, spreadability, and adhesion were analyzed statistically using Anova Single Factor with a confidence level of 95\%. The results showed that the F1 and F2 formulas with PVA concentrations of $10 \%$ and $12.5 \%$ were the optimum 
formulas as a mask base. Based on statistical tests, variations in the concentration of PVA significantly influence the parameters of mask adhesion with a p-value of $0.0001(<0.05)$, while the parameters of viscosity, $p H$, drying time, and dispersal yield was not significant differences.

Keywords: galangal extract, Alpinia galanga, peel-off gel mask

"Corresponding author:

Mar'atus Sholikhah

Program Studi S1 Farmasi Sekolah Tinggi Ilmu Farmasi Yayasan Pharmasi

Jalan Letnan Jendral Sarwo Edie Wibowo Km. 1 Plamongansari, Pucanggading, Semarang

E-mail: mara.tush@yahoo.com

\section{PENDAHULUAN}

Kesehatan kulit merupakan hal penting yang didambakan oleh banyak orang. Pencemaran atau polusi yang tinggi dapat menyebabkan masalah bagi kulit, demikian juga dengan paparan sinar matahari yang berlebih. Garis-garis kulit dan sel kulit mati dapat segera terbentuk apabila seseorang tidak rutin membersikan kulit wajah dan melakukan perawatan wajah. Perawatan wajah sederhana yang bisa dilakukan sendiri di rumah yakni menggunakan masker wajah (Rahim \& Nofiandi, 2014). Masker gel peel-off merupakan salah satu sediaan topikal yang digunakan pada wajah dengan cara dioleskan dengan tangan atau kuas yang apabila dibiarkan beberapa saat dapat mengering dan kencang sehingga dapat dilepas (Syarifah dkk., 2015). Prinsip dari masker tersebut ialah kemampuan pembentukan film saat menempel pada kulit sehingga pada saat masker kering akan membentuk lapisan film tipis, selanjutnya sel-sel kulit mati dan kotoran kulit akan terlepas dan terangkat bersama dengan film masker gel peel-off (Reveny dkk., 2016). Masker ini dapat digunakan untuk membersihkan, melembabkan kulit dan mengecilkan pori-pori serta melenturkan otot-otot wajah (Budiman dkk., 2017).

Salah satu bahan alam yang banyak diformulasikan ke dalam masker gel peel-off adalah bahan-bahan yang memiliki efek antioksidan (Reveny dkk., 2016). Senyawa 1'-asetoksikavikol asetat dan katekin yang terkandung dalam rimpang lengkuas terbukti memiliki kemampuan antioksidan. Menurut Mahae dan Chaiseri (2009), kandungan katekin dalam rimpang lengkuas sebesar 1,74 mg/g ekstrak dan 1'-asetoksikavikol asetat sebesar 10,56 mg/g ekstrak. Hasil studi menunjukkan bahwa ekstrak etanol rimpang lengkuas mempunyai $\mathrm{IC}_{50} 10,66 \mathrm{mg} / \mathrm{mL}$, hasil $\mathrm{IC}_{50}$ tersebut lebih baik dibandingkan dengan ekstrak air $(55,48 \mathrm{mg} / \mathrm{mL})$ dan minyak esensial $(455,43$ $\mathrm{mg} / \mathrm{mL}$ ) (Mahae dan Chaiseri, 2009). Aktivitas antioksidan tersebut perlu diaplikasikan ke dalam bentuk sediaan farmasi untuk meningkatkan estetika dan kemudahan dalam penggunaan, salah satunya dalam bentuk sediaan masker gel peel-off.

Karakteristik fisik sediaan masker gel peel-off dapat dipengaruhi oleh komponen penyusun yang digunakan dalam formula (Vieira, 2009). Beberapa bahan yang sering digunakan ialah polivinil alkohol PVA dan HPMC. Variasi konsentrasi PVA dan campuran kedua bahan tersebut diharapkan dapat menghasilkan tampilan fisik yang menarik, sediaan yang cepat mengering, kemampuan daya sebar yang luas, daya melekat yang baik, $\mathrm{pH}$ sediaan yang sesuai dengan kulit, dan viskositas yang optimum.

\section{METODE PENELITIAN}

\section{Alat dan Bahan}

Alat yang digunakan meliputi alat uji daya sebar, alat uji daya lekat, $\mathrm{pH}$ stik, viskometer Brookfield DV-I Prime, stopwatch, dan alat-alat gelas. Bahan yang digunakan meliputi PVA, 
HPMC, propilenglikol, metilparaben, propilparaben, dan akuades yang merupakan pharmaceutical technical grade serta ekstrak etanol lengkuas (koleksi STIKES Mandala Waluya Kendari).

\section{Jalannya Penelitian}

1. Optimasi Formula masker gel Peel-off

Sediaan masker gel peel-off terdiri dari tiga formula yang tertera pada tabel I. Masingmasing formula didesain dengan konsentrasi gelling agent yang berbeda (PVA) pada konsentrasi $10 \%, 12,5 \%$, dan $15 \%$.

Tabel I. Komposisi formula masker gel peel-off

\begin{tabular}{lccc}
\hline \multicolumn{1}{c}{ Bahan } & \multicolumn{3}{c}{ Formula (\%) } \\
\cline { 2 - 4 } & F1 & F2 & F3 \\
\hline Ekstrak lengkuas & 10 & 10 & 10 \\
PVA & 10 & 12,5 & 15 \\
HPMC & 1 & 1 & 1 \\
Propilenglikol & 10 & 10 & 10 \\
Metilparaben & 0,2 & 0,2 & 0,2 \\
Propilparaben & 0,05 & 0,05 & 0,05 \\
Akuades ad & 30 & 30 & 30 \\
\hline
\end{tabular}

\section{Formulasi masker}

Masker gel peel-off ekstrak lengkuas dibuat dengan cara HPMC dan PVA dikembangkan dalam air panas $\left(>80^{\circ} \mathrm{C}\right)$ kemudian campuran tersebut dihomogenkan dalam mortir. Pada wadah yang lain metilparaben dan propilparaben dilarutkan dalam propilenglikol dan ditambahkan ke dalam campuran PVA dan HPMC sedikit demi sedikit. Setelah homogen, ekstrak lengkuas selanjutnya ditambahkan dan dicukupkan dengan akuades hingga bobot $30 \mathrm{~g}$ (Zhelsiana dkk., 2016).

3. Evaluasi sediaan

\section{Uji organoleptis}

Sediaan masker gel peel-off ekstrak lengkuas kemudian dievaluasi fisika yang meliputi konsistensi, warna, dan bau (Zhelsiana dkk., 2016).

Uji homogenitas

Sejumlah sediaan di atas gelas objek dan ditutup dengan deekglas. Sediaan dikatakan homogen apabila tidak terdapat gumpalan atau partikel yang terlihat (Reveny dkk., 2016).

Uji $\mathrm{pH}$ sediaan

Uji ini dilakukan dengan menggunakan kertas indikator universal, sejumlah sediaan diambil menggunakan batang pengaduk dan digoreskan pada kertas indikator serta diamati perubahan warna yang terjadi. Nilai $\mathrm{pH}$ sediaan topikal yang dikehendaki berkisar antara 4,5-6,5 (Syarifah dkk., 2015).

Viskositas

Uji viskositas dilakukan untuk mengetahui tingkat kekentalan sampel, uji ini menggunakan alat viskometer brookfield. Ukuran spindel yang digunakan no 64 pada $100 \mathrm{rpm}$. Sejumlah sampel dimasukkan pada wadah kemudian spindel dicelupkan ke dalam wadah hingga tanda batas. Nilai cPs yang muncul pada monitor selanjutnya dicatat sebagai viskositas (Sukmawati dkk., 2013).

Daya sebar

Sampel sebanyak 0,5 g diletakkan pada kaca bulat berdiameter $15 \mathrm{~cm}$, kemudian kaca bagian atas ditimbang dan diletakkan di atas sampel (dibiarkan selama satu menit). Beban seberat 50 gram ditambahkan dan didiamkan 1 menit. Daya sebar sampel dicatat setiap dilakukan penambahan sampel. Penambahan beban 50 gram dilakukan hingga sampel memiliki daya sebar yang konstan (Cahyani dan Putri, 2017).

Waktu mengering 
Satu gram masker dioleskan pada kulit $(7 \mathrm{~cm} \times 7 \mathrm{~cm})$ dan dicatat waktu yang dibutuhkan oleh sampel untuk membentuk lapisan film, waktu dihitung menggunakan stopwatch (Cahyani dan Putri, 2017) (Zhelsiana dkk., 2016).

Daya lekat

Gelas objek ditentukan luasnya dan ditandai, sebanyak 0,2 gram masker diletakkan pada gelas objek dengan luas yang sudah ditentukan tersebut. Disiapkan gelas objek yang lain dan diletakkan di atas masker serta diberi beban $1 \mathrm{~kg}$ selama 5 menit. Sepasang gelas objek tersebut selanjutnya dipasang pada alat untuk uji daya lekat. Stopwatch dijalankan saat beban dilepaskan hingga kedua gelas objek tersebut terlepas (Cahyani dan Putri, 2017). Daya sebar sediaan gel yang baik berkisar antara 5-7 cm (Syarifah dkk., 2015).

\section{HASIL DAN PEMBAHASAN}

Karakterisasi fisik masker wajah peel-off yang dilakukan terdiri dari beberapa parameter meliputi uji organoleptis, homogenitas, viskositas, $\mathrm{pH}$ sediaan, waktu mengering, daya lekat, dan daya sebar. Hasil evaluasi beberapa parameter tersebut ditampilkan pada Tabel II.

Tabel II. Hasil evaluasi fisik masker gel peel-off ekstrak lengkuas

\begin{tabular}{llll}
\hline & \multicolumn{3}{c}{ Formula } \\
\cline { 2 - 4 } Parameter & F1 & F2 & F3 \\
\hline Organoleptis: & Kekuningan & Kekuningan & Kekuningan \\
Warna & Khas lengkuas & Khas lengkuas & Khas lengkuas \\
Bau & Encer & Agak encer & Kental \\
Konsistensi & Homogen & Homogen & Homogen \\
Homogenitas & $4813 \pm 90$ & $5066 \pm 48$ & $5800 \pm 82$ \\
Viskositas (cPs) & $5,25 \pm 0,02$ & $6,14 \pm 0,04$ & $6,15 \pm 0,03$ \\
pH sediaan & $23,67 \pm 0,58$ & $25,33 \pm 0,57$ & $26,33 \pm 2,15$ \\
Waktu mengering (menit) & $4,87 \pm 0,92$ & $10,45 \pm 2,32$ & $31,87 \pm 5,09$ \\
Daya lekat (detik) & $6,02 \pm 0,38$ & $5,366 \pm 0,157$ & $4,36 \pm 0,08$ \\
Daya sebar (cm) & & &
\end{tabular}

Hasil organoleptis sediaan menunjukkan bahwa ketiga formula mempunyai warna yang mirip (kekuningan) dan bau khas lengkuas. Konsistensi sediaan menunjukkan bahwa seiring peningkatan konsentrasi PVA maka konsistensi akan meningkat. Formula F3 memiliki konsentrasi PVA yang paling tinggi sehingga menghasilkan konsistensi yang paling kental.

Uji homogenitas menggambarkan ada atau tidaknya gumpalan atau bagian masker tidak homogen yang terlihat secara fisika. Berdasarkan uji homogenitas yang telah dilakukan diketahui bahwa formula masker F1, F2, dan F3 mempunyai tekstur yang homogen.

Konsentrasi PVA terlihat berpengaruh terhadap kemampuan daya sebar masker. Formula masker F1 yang mengandung PVA paling rendah di antara tiga formula diketahui menghasilkan daya sebar paling tinggi $(6,02 \pm 0,38 \mathrm{~cm})$. Hal ini sesuai dengan literatur, bahwa nilai viskositas berbanding terbalik dengan kemampuan daya sebar sediaan. Uji ini dilakukan dengan maksud untuk mengetahui kecepatan atau daya menyebar sediaan saat dioleskan ke permukaan kulit. Sediaan masker yang baik adalah setelah dioleskan maka akan segera menyebar dan kemampuan menyebarnya tinggi (Sukmawati dkk., 2013).

Kemampuan melekat sediaan topikal digunakan untuk mengukur kemampuan masker untuk menempel saat diaplikasikan pada kulit. Hasil pengamatan menunjukkan bahwa uji viskositas berhubungan dengan parameter kemampuan melekat sediaan masker. Menurut Martin dkk. (1993), kenaikan viskositas sediaan setengah padat akan diikuti dengan peningkatan daya lekat. Besarnya jumlah PVA diikuti dengan peningkatan serat polimernya maka air yang tertahan dan terikat pada pembentuk gel tersebut juga semakin banyak (Martin dkk., 1993). Menurut uji 
yang telah dilakukan, hasil daya lekat dipengaruhi oleh viskositas, seiring dengan viskositas yang tinggi maka kemampuan lekat sediaan juga meningkat. Viskositas memiliki peranan penting terhadap pelepasan atau difusi zat aktif dari sediaan (Andaryekti dkk., 2015).

Waktu pengeringan merupakan faktor penting yang memungkinkan pembentukan lapisan film sediaan masker gel peel-off. Waktu mengering yang baik sediaan masker gell peel-off berkisar antara 15-30 menit. Hasil uji ketiga formula menunjukkan bahwa formula masker F3 memiliki waktu mengering yang sedikit lebih lama. Hal ini berkaitan dengan viskositas sediaan, viskositas sediaan yang tinggi akan menghasilkan waktu mengering yang lebih panjang.

Parameter penting selanjutnya ialah $\mathrm{pH}$ sediaan. Karena $\mathrm{pH}$ kulit berkisar antara 4,5-6,5 maka $\mathrm{pH}$ sediaan topikal yang ideal berkisar pada $\mathrm{pH}$ tersebut (Muliyawan dan Surina, 2013). Variasi konsentrasi PVA terlihat berpengaruh terhadap nilai $\mathrm{pH}$ sediaan, berdasarkan pengamatan peningkatan jumlah PVA akan menurunkan $\mathrm{pH}$ sediaan.

Berdasarkan hasil formulasi dan pengamatan beberapa parameter fisik sediaan yang telah dilakukan, diketahui bahwa formula F1 dan F2 memenuhi persyaratan di setiap parameter uji sedangkan pada formula F3 terdapat satu parameter yang tidak memenuhi persyaratan yakni pada uji daya sebar. Dengan demikian, formula masker F1 dan F2 dengan konsentrasi PVA masingmasing $10 \%$ dan $12,5 \%$ merupakan formula optimum yang dapat menghasilkan karakteristik sediaan masker gel peel-off ekstrak lengkuas yang baik.

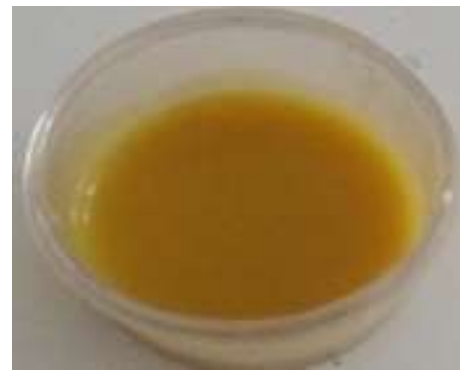

(a)

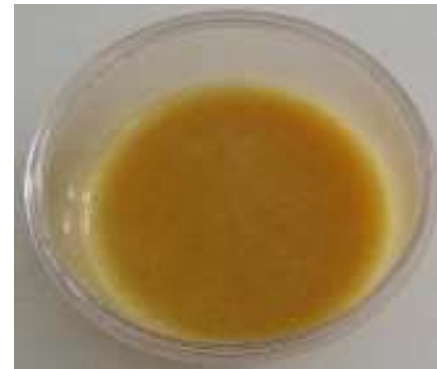

(b)

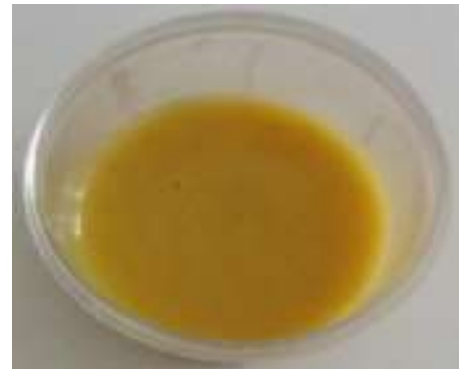

(c)

Gambar 1. Hasil sediaan masker gel peel-off ekstrak lengkuas, (a) F1; (b) F2; (c) F3

Data hasil uji parameter viskositas, waktu mengering, $\mathrm{pH}$ sediaan, daya sebar, dan daya lekat tiga formula tersebut selanjutnya dilakukan uji secara statistik menggunakan Anova Single Factor dengan taraf kepercayaan 95\%. Hasil analisis statistik menunjukkan bahwa variasi konsentrasi gelling agent PVA berpengaruh signifikan terhadap parameter daya lekat masker dengan nilai $p$-value sebesar 0,0001 $(<0,05)$, sedangkan parameter viskositas, $\mathrm{pH}$, waktu mengering, dan daya sebar untuk ketiga formula diketahui bahwa perbedaan nilai pada tiga formula tersebut tidak berbeda signifikan.

\section{KESIMPULAN}

Peningkatan jumlah PVA akan meningkatkan viskositas sediaan yang selanjutnya akan berpengaruh terhadap turunnya daya sebar dan naiknya kemampuan lekat serta waktu mengering sediaan baik pada masker F1, F2, dan F3. Formula masker F1 dan F2 dengan konsentrasi PVA masing-masing $10 \%$ dan 12,5\% merupakan formula optimum sebagai basis masker gel peel-off ekstrak lengkuas.

\section{DAFTAR PUSTAKA}

Andaryekti, R., Mufrod., Munisih, S., 2015, Pengaruh Basis Gel Sediaan Masker Ekstrak Daun Teh Hijau (Camellia sinensis, Linn.) pada Karakteristik Fisik dan Aktivitas Bakteri Staphylococcus aureus ATCC 25923, Majalah Farmaseutik, 11(2): 294-299. 
Budiman, A., Kusuma, A., Aulifa, D. L., 2017, Peel-off Gel Formulation from Black Mulberries (Morus nigra) Extract as Antiacne Mask, National Journal of Physiology, Pharmacy, and Pharmacology, 7(9): 1-8.

Cahyani, I. M dan Putri, I. D. C., 2017, Formulation of Peel-Off Gel From Extract of Curcuma Heyneana Val \& Zijp Using Carbopol 940, Journal of Pharmaceutical and Medical Sciences, 2(2): 48-51.

Mahae, $\mathrm{N}$ dan Chaiseri, S., 2009, Antioxidant Activities and Antioxidative Components in Extracts of Alpinia galanga (L.) Sw, Kasetsart Journal-Natural Sciences, 43(2): 358-369.

Martin, A., J. Swarbrick, dan Cammarata, A., 1993, Farmasi Fisik: Dasar-dasar Farmasi Fisik dalam Ilmu Farmasetik Edisi Ketiga, Penerjemah Yoshita, UI Press, Jakarta, 1124-1187.

Muliyawan, D., dan Surina, N, 2013, A-Z Tentang Kosmetik, Elex Media Komputindo, Jakarta, 4344

Rahim, F., dan Nofiandi, D., 2014, Formulasi Masker Peel Off Ekstrak Rimpang Rumput Teki (Cyperus rotundus L.) sebagai Anti Jerawat, Prosiding Seminar Nasional dan Workshop Perkembangan Terkini Sains Farmasi dan Klinik IV Tahun 2014, 64-73.

Reveny, J., Nazliniwaty., Umayah, R., 2016, Formulation of Peel-off Mask from Ethanol Extract of Water Spinach Leaves as Anti Aging, International Journal of PharmTech Research, 9(12): 554-559.

Sukmawati N. M., Arisanti C.I., dan Wijayanti N. P. A., 2013, Pengaruh Variasi Konsentrasi PVA, HPMC, dan Gliserin terhadap Sifat Fisika Masker Wajah Gel Peel-off Ekstrak Etanol 96\% Kulit Buah Manggis (Garcinia mangostana L.), Jurnal Farmasi Udayana, 2(3).

Syarifah, R. S., Mulyanti, D., Gadri, A., 2015, Formulasi Sediaan Masker Gel Peel-off Ekstrak Daun Pepaya (Carica papaya L.) Sebagai Antijerawat dan Uji Aktivitasnya Terhadap Bakteri Propionibacterium Acnes, Prosiding penelitian speSIA Unisba, 662-670.

Vieria, R. P., 2009, Physical And Physicochemical Stability Evaluation of Cosmetic Formulations Containing Soybean Extract Fermented by Bifidobacterium Animalis, Brazilian Journal of Pharmaceutical Sciences, 45(3); 515-525.

Zhelsiana, D. A., Pangestuti, Y. S., Nabilla, F., Lestari, P., Wikantyasning, R. K., 2016, Formulasi dan Evaluasi Sifat Fisik Masker Gel Pell-Off Lempung Bentonite, The 4 th University Research Coloquium, 42-45 